\title{
There But for the Strange Attractor of God
}

\section{Andy Walsh (1) \\ in Faith Across the Multiverse}

https://doi.org/10.54739/grm7

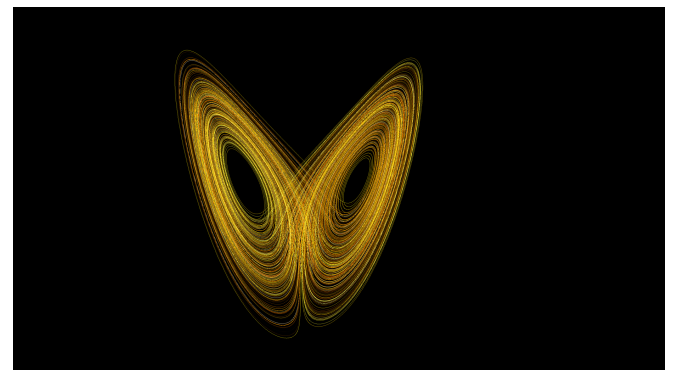

Public domain via Wiki Commons
W ar physical system? In our ball-throwing example, no matter how hard we throw the ball, it will always wind up in our friend's hands, even if sometimes it bounces off the roof of the house five doors down along the way. Or if you throw a basketball in the general vicinity of the rim, it will eventually make its way through the hoop.

Alas, basketball hoops in reality are far less forgiving and thus we marvel at the few who can guide a ball through them consistently. The same strict requirements attend many physical activities; all the conditions must be just right to get a positive outcome. Our intuition for the more abstract trajectory of our lives is often similarly constrained. We have to go to the right college, so we can get the right job. We have to marry the one partner who completes us. Life becomes a series of make-or-break choices.

So what would a strange attractor look like as part of the trajectory of our lives? And if we desire God to be involved in that trajectory, what

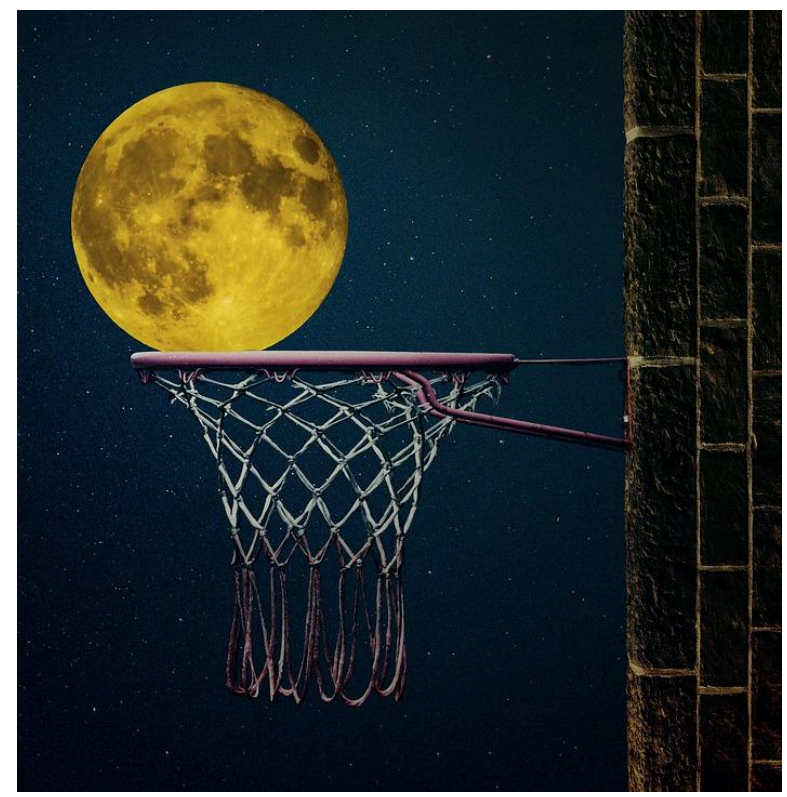

Basketballs and celestial bodies like the moon both follow predictable parabolic trajectories, but other dynamics are more chaotic.

Excerpt from Faith Across the Multiverse by Andy Walsh, ( $)$ 2018 by Hendrickson Publishers, Peabody,

Massachusetts. Used by permission. All rights reserved. would a strange attractor look like as part of his will? When we thought everything behaved like parabolas, then it seemed as if either God had a plan and everything was following it, in which case there was little room for free will and little need for grace and mercy, or we as humans have free will, in which case we can sin and be in need of grace and mercy, but then God's plan seems to need so many contingencies and adjustments that it becomes hard to see it as a plan at all. Obviously lots of people have come up with different ways to reconcile these various ideas, but the one that makes the most sense to me is to think of God's plan as being something like a strange attractor.

C

onsider what happens when we think of God's will in strange attractor terms. On the one hand, it is absolutely a well-defined, prespecified plan. The behavior that led to strange attractors was completely defined by our equations; we didn't have to make adjustments as we went. And yet on the other hand, there is room for free choice in the system as well. We can get off the pattern, and eventually events will come back to that pattern. There are still consequences to that choice, in that the exact spots within the pattern that get visited will change, but overall the system stays in the attractor.

Now perhaps a system that returns to an attractor still doesn't seem like freedom to you, if it is not possible to stay outside the pattern. I can understand that, and so I think it's probably most helpful to apply the strange attractor analogy to the state of the entire world. You can make individual choices for your own life, including whether you want to choose axioms for your life that allow for the God of the Bible or not. Those choices have real consequences for how future events play out. But the world itself will continue on in the same overall contours it was always following.

Let's see if this perspective helps us to understand the story in Exodus any better. We saw God asserting his sovereignty over the world and claiming responsibility for how events play out; our model is consistent with this idea. We saw Moses choose to decline the commission to speak to Pharaoh on his own; our model affirms that this is genuinely a choice on Moses' part and allows for such choices. That makes it easier to understand God's anger at Moses' choice, since it is something

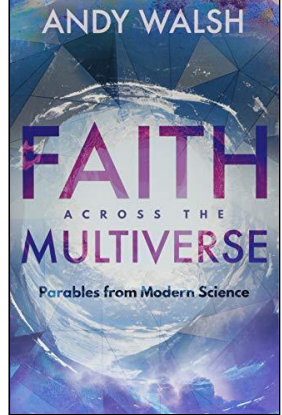


Moses has genuinely chosen without God having always intended for Moses to act thusly; our model indicates that Moses' choice will have real consequences, which may be suboptimal for Moses and/or other people in Moses' sphere of influence, and thus represent a true sin which would displease God. One of those consequences is that Aaron will accompany Moses to lead the Israelites out of exile, and it is Aaron who will later facilitate the worship of the golden calf in place

\section{References}

Gleick, James. Chaos: The Making of a New Science. (New York: Viking, 1987) of God while Moses communes with God on his own. If Aaron hadn't been Moses' spokesperson, perhaps he would not have later been seen as having the authority to condone the forging of the calf. Finally, we know that the nation of Israel was freed from its exile in Egypt; our model proposes that outcomes such as this will be resilient to individual choices.

Oord, Thomas Jay. The Uncontrolling Love of God: An Open and Relational Account of Providence. (Westmont: IVP Academic, 2015) 